\title{
Co-catalyzed $E-(\beta)$-selective hydrogermylation of terminal alkynes
}

\author{
Maxim R. Radzhabov and Neal P. Mankad* \\ Department of Chemistry, University of Illinois at Chicago 845 W. Taylor St., Chicago, IL 60607, USA. \\ KEYWORDS: regioselective, hydrogermylation, terminal alkynes, cobalt, tributylgermanium hydride.
}

\begin{abstract}
We demonstrated unprecedentedly that Co complexes can catalyze hydrogermylation of alkynes. Subsequently, a selective, accessible method was developed to synthesize E-( $\beta$ )-vinyl(trialkyl)germanes from various terminal alkynes with high yields. As shown on multiple examples, the developed method demonstrates broad functional group tolerance and practical utility for late-stage hydrogermylation of drugs and natural products. The method is compatible with alkynes bearing both aryl and alkyl substituents, providing unrivaled selectivity for previously challenging $1^{\circ}$ alkyl-substituted alkynes. Moreover, the catalyst used in this method, $\mathrm{Co}_{2}(\mathrm{CO})_{8}$, is a cheap and commercially available reagent. Conducted mechanistic studies supported syn-addition of $\mathrm{Bu}_{3} \mathrm{GeH}$ to an alkyne $\pi$-complex.
\end{abstract}

C-C bond formation and functional group transformation reactions make the basis of modern organic chemistry since the latter half of the twentieth century. Among those methods transition metal-catalyzed reactions, such as Pdcatalyzed cross-coupling, hold a special, prominent position. Despite enormous success in this area, the need for more rapid, selective, advanced synthetic methodologies drives search for new coupling partners. Recently, organogermanes ${ }^{1-5}$ have emerged as perspective coupling partners to circumvent limitations of traditional organozinc and organomagnesium reagents ${ }^{6,7}$ (low functional group tolerance); organosilanes ${ }^{8}$ (low reactivity), organostannanes ${ }^{9-11}$ (acute toxicity: endocrine disruptors, immunotoxicants, carcinogens and obesogens); and organoboronic acids $^{12,13}$ (acid/base sensitivity). In this regard, vinylgermanes are of particular interest as versatile synthetic building blocks due to their low toxicity, ${ }^{14}$ resistance to protonolysis, ${ }^{15}$ and benchtop stability. ${ }^{16}$

Hydrofunctionalization of alkynes is a simple, highly atom-economical approach to many useful synthetic blocks. One of major challenges of hydrofunctionalization is product selectivity control, including Markovnikov vs. antiMarkovnikov regiochemistry and $\mathrm{Z}$ vs. E stereochemistry. Vinylgermanes proved to be useful synthetic blocks, which can be converted to vinylhalides with retention of the double-bond geometry ${ }^{17}$ and used as partners in Pd-catalyzed coupling. ${ }^{18,19}$ Thus, catalytic methods for producing vinylgermanes with high regio- and stereoselectivity are desirable.

Albeit a variety of catalysts has been studied to selectively perform hydrogermylation of alkynes since the middle of the 20th century, ${ }^{20}$ control over regio- and stereoselectivity still remains a very challenging problem, limiting development of vinylgermane chemistry. In many cases selectivity is controlled by specific reaction conditions or functional groups,19,21-24 whereas in absence of thereof selectivity is usually moderate. Studied hydrogermylation catalysts include Lewis acids; precious metals like Pd, $\mathrm{Ru}$, $\mathrm{Rh}$, and Pt; ${ }^{15}$ and earth-abundant metals, such as $\mathrm{Mn}$ and Fe (Figure 1). Lewis acids (Figure 1a), represented by boron compounds, tend to yield only Z- $\beta$ isomers ( $\alpha$ for propiolates) if trialkylgermanes are used, ${ }^{17}$ but can generate germyl radicals from $\mathrm{Ph}_{3} \mathrm{GeH}$ and yield both $\mathrm{Z}-\beta$ and $\mathrm{E}-\beta$ (depending on reaction temperature). ${ }^{25}$ Among precious metals, Pd catalysis have been studied especially well.

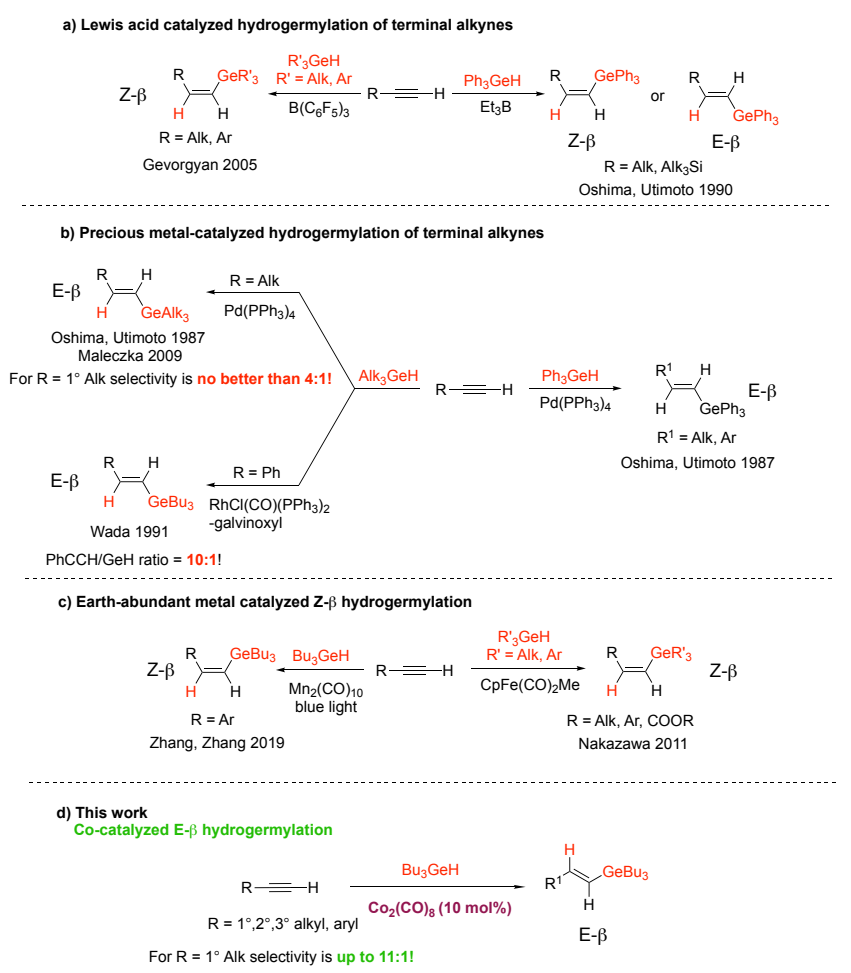

Figure 1. Hydrogermylation of terminal alkynes.

Thus, Oshima and Utimoto 26 demonstrated that $\mathrm{Pd}\left(\mathrm{PPh}_{3}\right)_{4}$ catalysts can yield E- $\beta$ isomers with good 
Table 1. Optimization of the reaction conditions ${ }^{a}$

\begin{tabular}{|c|c|c|c|c|c|c|c|c|c|c|}
\hline \multirow[b]{2}{*}{ Entry } & $\begin{array}{r} \\
\text { cate } \\
\text { co-ce } \\
\text { sol }\end{array}$ & $\begin{array}{l}{ }_{3} \mathrm{GeH} \\
\text { st }(\mathrm{mol} \%) \\
\text { lyst }(\mathrm{mol} \%) \\
\text { nt, t }\left({ }^{\circ} \mathrm{C}\right)\end{array}$ & & & $\begin{array}{c}7 \\
3 a\end{array}$ & $E-\beta)$ & \multicolumn{2}{|c|}{$\begin{array}{l}+Y_{7} \overbrace{\mathrm{GeBu}_{3}} \\
\mathbf{4 a}(\mathrm{Z}-\beta)\end{array}$} & \multirow{2}{*}{ 3a (\%) } & \multirow{2}{*}{ 4a (\%) } \\
\hline & Catalytic system & $\mathrm{T}\left({ }^{\circ} \mathrm{C}\right)$ & 1a eq. & & $\mathrm{u}_{3} \mathrm{GeH}$ (eq.) & Time & Solvent & $2 \mathbf{a}(\%)$ & & \\
\hline 1 & IMesCuCl (12\%), KFp (8\%) & -10 & 1.0 & & 1.2 & $12 \mathrm{~h}$ & toluene & 1 & 2 & 24 \\
\hline 2 & IMesCuCl (10\%), $\mathrm{NaMn}(\mathrm{CO})_{5}(10 \%)$ & 110 & 1.0 & & 1.2 & $4 \mathrm{~h}$ & toluene & 0 & 0 & traces \\
\hline 3 & IMesCuCl (10\%), $\mathrm{NaCo}(\mathrm{CO})_{4}(10 \%)$ & 110 & 1.0 & & 1.2 & $4 \mathrm{~h}$ & toluene & 23 & 22 & 1 \\
\hline 8 & $\mathrm{Fe}(\mathrm{CO})_{5}(10 \%)$ & 100 & 1.1 & & 1.0 & $15 \mathrm{~h}$ & toluene & 6 & 7 & 2 \\
\hline 9 & $\mathrm{Mn}_{2}(\mathrm{CO})_{10}(10 \%)$ & $\mathrm{RT}, \mathrm{hv}^{b}$ & 1.0 & & 1.2 & $15 \mathrm{~h}$ & DCM & traces & 2 & 20 \\
\hline 10 & $\mathrm{Co}_{2}(\mathrm{CO})_{8}(10 \%)$ & $\mathrm{RT}, \mathrm{hv}^{b}$ & 1.0 & & 1.2 & $15 \mathrm{~h}$ & $\mathrm{DCM}$ & 16 & 24 & 16 \\
\hline 11 & $\mathrm{Co}_{2}(\mathrm{CO})_{8}(10 \%)$ & 85 & 1.0 & & 1.2 & $15 \mathrm{~h}$ & DCE & 10 & 55 & 6 \\
\hline 12 & $\mathrm{CpCo}(\mathrm{CO})_{2}(10 \%)$ & 85 & 1.0 & & 1.2 & $15 \mathrm{~h}$ & DCE & 2 & 5 & 5 \\
\hline 13 & $\mathrm{Co}_{2}(\mathrm{CO})_{8}(10 \%)$ & 85 & 1.0 & & 1.0 & $15 \mathrm{~h}$ & DCE & 8 & 80 & traces \\
\hline 14 & $\mathrm{Co}_{2}(\mathrm{CO})_{8}(10 \%)$ & 85 & 1.1 & & 1.0 & $15 \mathrm{~h}$ & DCE & 8 & 90 & 0 \\
\hline 15 & {$\left[\mathrm{Co}(\mathrm{CO})_{3} \mathrm{PEt}_{3}\right]_{2}(10 \%)$} & 85 & 1.1 & & 1.0 & $15 \mathrm{~h}$ & DCE & 11 & 65 & 2 \\
\hline 16 & $\mathrm{NaCo}(\mathrm{CO})_{4}(10 \%)$ & 85 & 1.1 & & 1.0 & $15 \mathrm{~h}$ & DCE & 20 & 80 & 0 \\
\hline
\end{tabular}

${ }^{a}$ The reaction was performed on a $0.2 \mathrm{mmol}$ scale. Yields were determined by ${ }^{1} \mathrm{H}$ NMR integration of isolated mixtures against an

internal standard. ${ }^{b}$ Light source: blue LED strip lights (DC 12V 2A power supply).

selectivity for $\mathrm{Ph}_{3} \mathrm{GeH}$, but in the case of trialkylgermanes selectivity was reported to be only $4: 1(\beta / \alpha)$ for primary alkylacetylenes (Figure 1b). In 2009, Maleczka ${ }^{18}$ reported that this Pd catalyst affords only E- $\beta$ isomer for tertiary alkylacetylenes, but for unhindered alkynes selectivity still remained no more than $4: 1$. E- $\beta$ - and $\alpha$-selective hydrogermylation of phenylacetylene with tri-nbutylgermane, $\mathrm{Bu}_{3} \mathrm{GeH}$, by $\mathrm{Rh}$ catalysts was reported by Wada in 1991, though this reaction requires $10 \mathrm{eq}$ of PhCCH. ${ }^{27}$ E- $\beta$ selective Ru-catalyzed dehydrogenative germylation of styrene with $\mathrm{Bu}_{3} \mathrm{GeH}$ was demonstrated by Murai and Seki, but, just like the previous case, this reaction requires 10 eq of styrene for high selectivity. ${ }^{28}$

Given the limitations of precious metal-catalyzed hydrogermylation, there exists an opportunity for earthabundant metal catalysis, but this has been studied to a lesser extent and is only represented by Mn and Fe (Figure 1c). In 2011, Nakazawa demonstrated that Fe catalysts yield $\mathrm{Z}-\beta$ isomers for both $\mathrm{Bu}_{3} \mathrm{GeH}$ and $\mathrm{Ph}_{3} \mathrm{GeH}$ and aryland alkylacetylenes with excellent yields and selectivity ${ }^{29}$.
Very recently, in 2019, Zhang and Zhang reported visible light-initiated, Mn-catalyzed, Z- $\beta$ selective hydrogermylation of arylalkynes with $\mathrm{Bu}_{3} \mathrm{GeH}^{30}$

Herein, we report a Co-catalyzed, E- $\beta$ selective hydrogermylation of alkyl- and arylacetylenes with $\mathrm{Bu}_{3} \mathrm{GeH}$ (Figure 1d), a new method that allowed us to obtain E- $\beta$ isomers for primary alkylacetylenes with selectivity by far surpassing all existing methods.

Initially, we believed that an approach similar to that previously reported by our group for hydrostannylation ${ }^{31}$ could be developed for trialkylgermanium hydrides, and thus began our investigation using heterobimetallic (NHC)Cu-[Mco] complexes (which can be generated in situ from ( $\mathrm{NHC}) \mathrm{CuCl}$ and anionic metal carbonyls) to catalyze the reaction between 1-decyne and $\mathrm{Bu}_{3} \mathrm{GeH}$. Initial experiments (Table 1, entries 1 and 2) revealed that no product was forming when $\mathrm{Na}\left[\mathrm{Mn}(\mathrm{CO})_{6}\right]$ was used as a co-catalyst; however, some amount of the Z- $\beta$ isomer $\mathbf{4 a}$ was observed with

$\mathrm{K}[\mathrm{Fp}]$. 


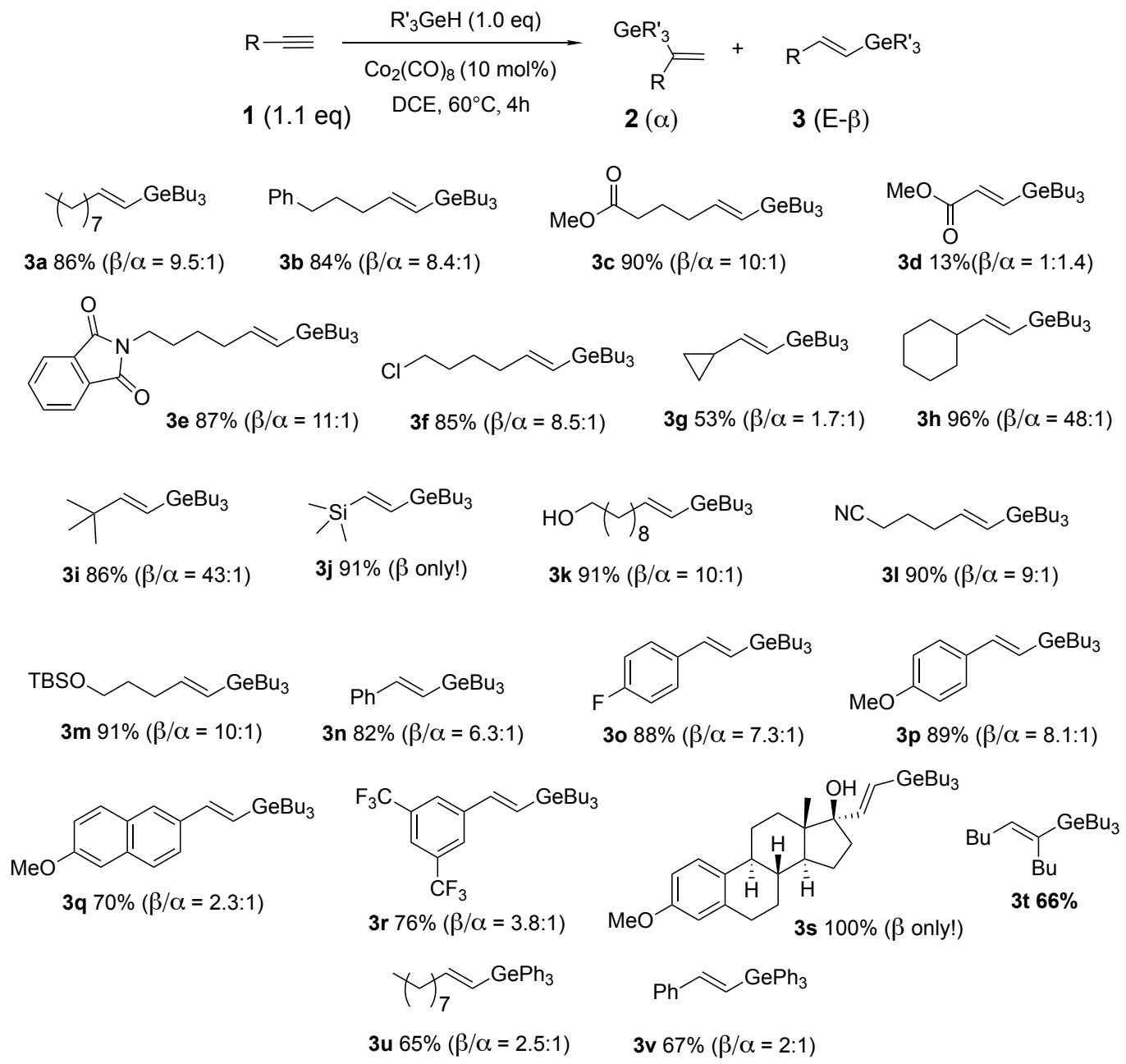

Figure 2. Hydrogermylation of various alkynes using the $\mathrm{Co}_{2}(\mathrm{CO})_{8}$ catalyst (reaction scope). The reaction was performed on a $0.2 \mathrm{mmol}$ scale. Yields and ( $\beta / \alpha$ ratios) were determined by ${ }^{1} \mathrm{H}$ NMR integration of isolated mixtures against an internal standard (isolated yields are reported in the SI).

Further screening of anionic metal carbonyls revealed that the reaction with $\mathrm{Na}\left[\mathrm{Co}(\mathrm{CO})_{4}\right]$ (entry 3 ) yielded noticeable amounts of the isomers $\alpha(\mathbf{2 a})$ and E- $\beta$ (3a), alas with no selectivity (1:1). To date this is the first example of a reported Co-catalyzed hydrogermylation reaction. Other metal carbonyls, such as $\mathrm{NaCrCp}(\mathrm{CO})_{3}, \mathrm{NaWCp}(\mathrm{CO})_{3}$, NaM$\mathrm{oCp}(\mathrm{CO})_{3}$ (please see SI for more information) yielded no products at all.

A control experiment (entry 4) showed that the presence of the (NHC)CuCl is not required. Since full conversion was already achieved, we believed that better regioselectivity could be reached with altering reaction temperatures and increasing reaction time. We found out that decreasing reaction temperature gives lower yields for both $\alpha(2 a)$ and E- $\beta$ (3a) isomers (entries 5, 6). Curiously, lower temperatures favor formation of the Z- $\beta$ isomer 4a (up to $40 \%$ ), thus allowing thermal control over Z/E regioselectivity $(\mathrm{Z} / \mathrm{E}=8: 1)$ of this reaction.

Knowing that anionic Co carbonyl complexes can catalyze hydrogermylation, we decided to study other structurally similar complexes. Since many efficient synthetic protocols for the Z- $\beta$ isomer $\mathbf{4 a}$ have already been developed before, we mostly focused on the somewhat less available isomers $\alpha$ (2a) and challenging E- $\beta$ (3a). Substituting a $\mathrm{CO}$ ligand in the original $\mathrm{NaCo}(\mathrm{CO})_{4}$ complex with a triphenylphosphine $\mathrm{PPh}_{3}$ (entry 7) increased $\beta / \alpha$ selectivity (from 1:1 to $2: 1$ ), but decreased overall conversion. The iron complex $\mathrm{Fe}(\mathrm{CO})_{5}$ demonstrated almost no catalytic activity (entry 8).

Visible light-induced $\mathrm{Mn}_{2}(\mathrm{CO})_{10}$-catalyzed radical hydrogermylation of arylalkynes ${ }^{30}$ has never been reported for alkylalkynes. Therefore, we decided to try the reported conditions with alkylalkynes using $\mathrm{Mn}_{2}(\mathrm{CO})_{10}$ (entry 9) as well as a related Co catalyst, $\mathrm{Co}_{2}(\mathrm{CO})_{8}$ (entry 10). We found that $\mathrm{Mn}$-catalyzed reaction mostly yields Z- $\beta$ product with great selectivity $(\mathrm{Z} / \mathrm{E}=10: 1)$, albeit low conversion $(\sim 22 \%)$. Under the same conditions $\mathrm{Co}_{2}(\mathrm{CO})_{8}$ (entry 10) demonstrated somewhat better conversion $(\sim 55 \%)$ but essentially no selectivity, giving all three isomers $\mathbf{2 a}$, 3a and $\mathbf{4 a}$.

The same set of reagents (with solvent changed to DCE to withstand higher temperatures), being activated ther- 
mally (entry 11), performed much better and mostly yielded the desired E- $\beta$ isomer (3a) with good selectivity $(\beta / \alpha=$ $5.5: 1)$ and overall conversion $(\sim 70 \%)$. Sterically bulkier $\mathrm{CpCo}(\mathrm{CO})_{2}$, on the other hand, demonstrated little catalytical activity (entry 12).

With promising results in hand, we decided to further optimize conditions for the thermal $\mathrm{Co}_{2}(\mathrm{CO})_{8}$-catalyzed hydrogermylation. In the original reaction (entry 11) we observed some noticeable amounts of some unidentified by-product (initially believed to be 1,2-bisgermyldecane). Changing stoichiometric ratio of reagents $\mathrm{Bu}_{3} \mathrm{GeH} / 1$ decyne from 1.2:1.0 eq. to 1.0:1.1 eq. solved that problem and significantly boosted the reaction selectivity and conversion (entries 13, 14).

Attempts to modify $\mathrm{Co}_{2}(\mathrm{CO})_{8}$ with trialkylphosphine ligands (like $\mathrm{Na}\left[\mathrm{Co}(\mathrm{CO})_{3} \mathrm{PPh}_{3}\right]$ ) demonstrated that $\left[\mathrm{Co}(\mathrm{CO})_{3} \mathrm{PEt}_{3}\right]_{2}$ (entry 15 ) gives yields and selectivity generally comparable to the original catalyst, albeit worse. Since $\mathrm{Co}_{2}(\mathrm{CO})_{8}$ worked very well in 1,2-dichloroethane (DCE), we decided to check effects of different solvents at respective reflux temperatures with the original model $\mathrm{NaCo}(\mathrm{CO})_{4}$ system. Surprisingly enough, the model system performed much better in DCE (entry 16) than in toluene and other solvents (more details in the SI), with great conversion and moderate selectivity $(\beta / \alpha=4: 1)$. This experiment demonstrated importance of this solvent for the studied reaction.

We also found out that the temperature of the reaction could be brought down to $60^{\circ} \mathrm{C}$ (entry 17), but not below. Lesser catalyst loading (entry 18) slightly decreases the selectivity of the reaction (probably due to the lower concentration of the active catalytic species), but greater loading (entry 19) does not have any noticeable effect. It is also possible to bring the reaction time down from 15 hours to just 4 (entry 20).

Under optimal conditions, we tested hydrogermylation for a range of alkyl and aryl-substituted alkynes with various functional groups (Figure 2). The vast majority of tested alkynes smoothly underwent anti-Markovnikov hydrogermylation to afford E-( $\beta$ )-vinylgermanes with good regioselectivity and in excellent yields. Apparently among alkyl-substituted vital functional groups, ester (3c), amide (phthalimide $\mathbf{3 e}$ ), silyl (3j), and silyl ether (3m) are very well tolerated. Halide groups (3f), strongly coordinating alkyl nitrile (31), and even an unprotected alcohol group (3k) are totally compatible with the reaction conditions. Bulky tertiary and secondary alkyl substituents (such as $\mathbf{3 h}, \mathbf{3 i})$ greatly increase selectivity of the reaction (with the unfortunate exception of cyclopropylacetylene $\mathbf{3 g}$, which gave low selectivity). It is also interesting to note that low selectivity and yields were observed for methyl propiolate (3d), but propiolates generally tend to yield $\alpha$ products. ${ }^{17}$ Internal alkynes do react under given conditions, though with somewhat lower yields (3t), probably due to substantial steric hindrance. Remarkably, the reaction proved to be regiospecific for silyl acetylene (3j) and especially Mestranol (3s), as no traces of the undesired $\alpha$ isomer were observed in corresponding NMR spectra. Therefore, our method demonstrated its practical utility for late-stage hydrogermylation of natural compounds and pharmaceuticals. Mestranol, in particular, is known as an estrogen medication used in birth control pills, menopausal hormone therapy, and the treatment of menstrual disorders. ${ }^{32,33}$

Aryl-substituted alkynes were also tested under the same conditions (Figure 2), giving E-( $\beta$ )-vinylgermanes as the major products with good yields. Investigation of the substrate scope showed that activated aryl alkynes with electron-donating or electron-withdrawing groups have higher selectivity for $E-(\beta)$ isomers $(\mathbf{3 o}, \mathbf{3 p})$, compared to non-activated phenyl acetylene (3n). However, too strong electron-withdrawing groups can decrease selectivity (3r). Poor selectivity was also observed for ethynyl naphthalene (3q); we speculate that the naphthalene core may react with the catalyst to form corresponding cobaltnaphthalene derivatives that can affect selectivity. ${ }^{34}$

We also investigated reactivity of triphenylgermanium hydride, $\mathrm{Ph}_{3} \mathrm{GeH}$, under the studied conditions (Figure 2), but unfortunately only moderate yields and poor selectivity were obtained with 1-decyne and phenyl acetylene $(3 \mathbf{u}$, 3v). Probably the reaction mechanism for $\mathrm{Ph}_{3} \mathrm{GeH}$ is different from $\mathrm{Bu}_{3} \mathrm{GeH}$, as the former is prone to form radicals. ${ }^{25}$

We would like to propose the following mechanism (Figure 3) for our E-( $(\beta)$-selective hydrogermylation, based on analogies found in the literature. ${ }^{35-37}$ Reaction between $\mathrm{Co}_{2}(\mathrm{CO})_{8}$ and $\mathrm{Bu}_{3} \mathrm{GeH}$ most likely generates cobalt tetracarbonyl hydride, $\mathrm{HCo}(\mathrm{CO})_{4}$, and $\mathrm{Bu}_{3} \mathrm{Ge}-\mathrm{Co}(\mathrm{CO})_{4}$ (analogous to that studied by Jeannin), ${ }^{38}$ and then probably both cores can catalyze the hydrogermylation reaction (albeit with different selectivity and efficiency).

Just like in well-known hydroformylation, the cycles begin with thermally induced dissociation of the carbonyl $\mathrm{CO}$ from original $\mathrm{HCo}(\mathrm{CO})_{4} \mathbf{A}$ and $\mathrm{Bu}_{3} \mathrm{Ge}-\mathrm{Co}(\mathrm{CO})_{4} \mathbf{F}$ complexes to generative active 16-electron species $\mathbf{B}$ and $\mathbf{G}$, respectively (Figure 3). Then addition of an alkyne generates corresponding $\pi$-complexes $\mathbf{C}$ and $\mathbf{H}$. For the $\mathrm{HCo}(\mathrm{CO})_{4}$ pathway, a hydride complex $\mathbf{C}$ easily undergoes migratory insertion to form a new 16-electron alkenyl tricarbonyl complex D. The coordinated alkyne can adopt two different orientations, but the migratory insertion of $\mathbf{C}$ is favored due to formation of a stronger Co-C bond in $\mathbf{D}$. Then complex D undergoes oxidative addition with $\mathrm{Bu}_{3} \mathrm{GeH}$ to give a new 18-electron germylvinyl(tricarbonyl)cobalt $\mathbf{E}$, which in its own turn releases the desired alkene by reductive elimination.

It is quite probable that $\mathrm{Bu}_{3} \mathrm{Ge}-\mathrm{Co}(\mathrm{CO})_{4} \mathbf{F}$ actively takes part in the studied reaction, since higher amounts of $\mathrm{Bu}_{3} \mathrm{GeH}$ significantly change reaction yields and selectivity (please see SI). In this pathway, a tributylgermyl group in $\mathbf{H}$ can undergo migratory insertion (similarly to the $\left.\mathrm{HCo}(\mathrm{CO})_{4}\right)$, forming a new 16 -electron I. That new species can undergo oxidative addition with another molecule of $\mathrm{Bu}_{3} \mathrm{GeH}$ to give 18-electron species with a stronger Co-C bond $\mathbf{J}$, which then releases the product via reductive elimination and starts the cycle anew. 
We conducted some experiments to obtain additional support for the proposed mechanism (Table 2). The first test was to study susceptibility of the reaction to acids and

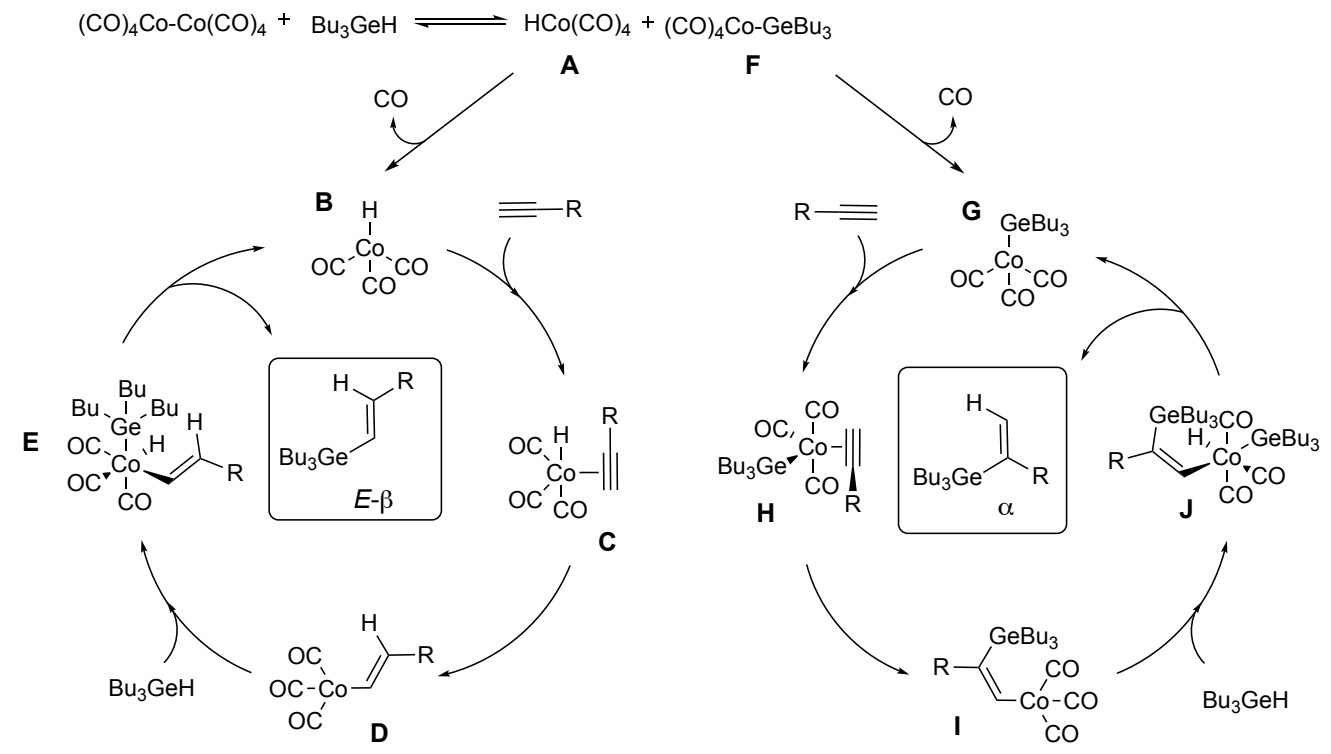

Figure 3. Plausible mechanism for the Co-catalyzed hydrogermylation.

bases present in the reaction mixture, since we believe the key intermediate is cobalt tetracarbonyl hydride, $\mathrm{HCo}(\mathrm{CO})_{4}$, which is known to be acidic. ${ }^{39}$ While acids have little to no effect on the reaction (for both $\mathrm{NaCo}(\mathrm{CO})_{4}$ and $\mathrm{Co}_{2}(\mathrm{CO})_{8}$, entries 1 and 3), strong bases like tBuONa inhibit the reaction (entry 2). It is worth noting that $\mathrm{NaCo}(\mathrm{CO})_{4}$ demonstrated much higher selectivity for the E- $(\beta)$ product in 1,2-dichloroethane (DCE). Previously Chatani and Murai reported that $\mathrm{HSiR}_{3} / \mathrm{Co}_{2}(\mathrm{CO})_{8}$ systems can react with oxygen-containing compounds to form cobalt complexes containing a carbon-cobalt bond.40,41 We believe that a similar reaction of $\mathrm{NaCo}(\mathrm{CO})_{4}$ with $\mathrm{DCE}$ may take place, where an alkylcobalt complex is generated first (via $\mathrm{Sn} 2$ mechanism), only to afford $\mathrm{HCo}(\mathrm{CO})_{4}$ via subsequent $\beta$-hydride elimination.

Importance of $\mathrm{HCo}(\mathrm{CO})_{4}$ for this reaction was further demonstrated in the following series of experiments. To further probe the cobalt hydride mechanism, we synthesized a triphenylsilylcobalt complex, $\mathrm{Ph}_{3} \mathrm{Si}-\mathrm{Co}(\mathrm{CO})_{4}$, for subsequent alcoholysis of the cobalt-silicon bond (to generate $\mathrm{HCo}(\mathrm{CO})_{4}$ in situ according to a known procedure ${ }^{42}$ ) under different conditions. Initial experiments in DME (which was used in the original procedure, entries 4,5 ) showed practically no difference, no matter if methanol was present or not. However, the situation changes dramatically when toluene was used as the solvent (entries 6, $7)$. Overall conversion and selectivity for the $E-(\beta)$ isomer in toluene are significantly lower $(\beta / \alpha=\sim 5: 1$, compared to 8:1 in DME); however, presence of $\mathrm{MeOH}$ boosts selectivity back to "normal" 8:1. It is interesting to note that sometimes, when excess amounts of an alkyne were used, aldehyde peaks were evident in ${ }^{1} \mathrm{H}$ NMR spectra, indicating hydroformylation side reactions consistent with the presence of $\mathrm{HCo}(\mathrm{CO})_{4}$ in situ.
Table 2. Mechanistic studies ${ }^{\mathrm{a}}$

\begin{tabular}{|c|c|c|c|c|c|c|}
\hline $\begin{array}{r}x_{7} \\
\text { 1a (1.1 }\end{array}$ & $\begin{array}{l}\mathrm{Bu}_{3} \mathrm{GeH}(1.0 \mathrm{eq}) \\
\text { catalyst }(10 \mathrm{~mol} \%) \\
\text { additive }(10 \mathrm{~mol} \%) \\
\text { solvent, } \mathrm{t}\left({ }^{\circ} \mathrm{C}\right), 15 \mathrm{~h}\end{array}$ & & 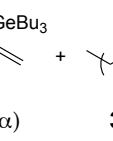 & $3 a(E-\beta)$ & & $\overbrace{(Z-\beta)}$ \\
\hline Entry & Catalytic system & $\begin{array}{c}\mathrm{T} \\
\left({ }^{\circ} \mathrm{C}\right) \\
\end{array}$ & Solvent & $\begin{array}{l}2 a \\
(\%)\end{array}$ & $\begin{array}{l}3 a \\
(\%)\end{array}$ & $\begin{array}{l}4 a \\
(\%)\end{array}$ \\
\hline 1 & $\begin{array}{c}\mathrm{NaCo}(\mathrm{CO})_{4}+ \\
\mathrm{PhCOOH}\end{array}$ & 85 & DCE & 9 & 82 & 0 \\
\hline 2 & $\begin{array}{l}\mathrm{NaCo}(\mathrm{CO})_{4}+ \\
\text { tBuONa }\end{array}$ & 100 & toluene & 5 & 3 & 2 \\
\hline 3 & $\begin{array}{c}\mathrm{Co}_{2}(\mathrm{CO})_{8}+ \\
\mathrm{PhCOOH}\end{array}$ & 60 & DCE & 9 & 91 & 0 \\
\hline 4 & $\mathrm{Ph}_{3} \mathrm{Si}-\mathrm{Co}(\mathrm{CO})_{4}$ & 85 & DME & 11 & 88 & 0 \\
\hline 5 & $\begin{array}{c}\mathrm{Ph}_{3} \mathrm{Si}-\mathrm{Co}(\mathrm{CO})_{4}+ \\
\mathrm{MeOH}\end{array}$ & 85 & DME & 10 & 87 & 0 \\
\hline 6 & $\mathrm{Ph}_{3} \mathrm{Si}-\mathrm{Co}(\mathrm{CO})_{4}$ & 100 & toluene & 15 & 68 & 2 \\
\hline 7 & $\begin{array}{c}\mathrm{Ph}_{3} \mathrm{Si}-\mathrm{Co}(\mathrm{CO})_{4}+ \\
\mathrm{MeOH}\end{array}$ & 100 & toluene & 8 & 66 & 1 \\
\hline 8 & $\mathrm{Co}(\mathrm{TPP})^{b}$ & 100 & toluene & 0 & 0 & 0 \\
\hline 9 & $\mathrm{Co}(\mathrm{Pc})^{c}$ & 100 & toluene & 0 & 0 & 0 \\
\hline
\end{tabular}

${ }^{a}$ The reaction was performed on a $0.2 \mathrm{mmol}$ scale. Yields were determined by ${ }^{1} \mathrm{H}$ NMR integration of isolated mixtures against an internal standard. ${ }^{b}$ Cobalt(II) tetraphenylporphyrin; ${ }^{\circ}$ Cobalt(II) phthalocyanine.

Radical pathways can be ruled out since direct visible light-induced generation of radicals from $\mathrm{Co}_{2}(\mathrm{CO})_{8}$ proved to be unselective (Table 1, entry 10). To further support this claim, we tested stable metalloradicals cobalt(II) tetraphenylporphyrin (TPP) and cobalt(II) phthalocyanine (Pc) as catalysts (entries 8, 9), widely used in radical reactions. ${ }^{43}$ Those complexes demonstrated absolutely no catalytic activity in given conditions, thus supporting non-radical mechanistic pathways 
and emphasizing the importance of availability of ciscoordination sites for the reaction to occur.

Based on obtained experimental data, we can conclude that the studied reaction does not proceed via $\eta^{1-}$ vinylidene Co complex, since such a pathway would yield a mixture of $\mathrm{E} / \mathrm{Z}-(\beta)$ isomers, ${ }^{44}$ whereas for most $\mathrm{Co}_{2}(\mathrm{CO})_{8}$-catalyzed reactions we observed a mixture of $\alpha$ and $\mathrm{E}-\beta$ isomers with little to no Z- $(\beta)$ product. However, the $\eta^{1}$-vinylidene pathway still may be operative when other catalysts are used, especially at lower temperatures (Table 1 , entry 6).

In summary, for the first time Co complexes were demonstrated as viable catalysts of a hydrogermylation reaction. We have developed a novel, selective, accessible protocol for the synthesis of previously very limited E- $(\beta)$-vinyl(trialkyl)germanes, thus laying the basis for the flourishing of (trialkyl)germane chemistry. With dicobalt octacarbonyl, $\mathrm{Co}_{2}(\mathrm{CO})_{8}$, as a cheap and commercially available catalyst, different $\mathrm{E}-(\beta)$ vinyl(trialkyl)germanes were directly synthesized in high yield and with good selectivity from accessible alkyl- and arylacetylenes and $\mathrm{Bu}_{3} \mathrm{GeH}$ as the germanium source. Tertiary, secondary and, most importantly, primary alkylacetylenes react well and with high selectivity under optimized conditions. Arylacetylenes are also applicable under reaction conditions. The protocol is also suitable for late stages of total synthesis of natural products and drugs, as was demonstrated by the regioselective hydrogermylation of Mestranol. Obtained data and mechanistic studies supported syn-addition of $\mathrm{Bu}_{3} \mathrm{GeH}$ to a $\pi$-alkyne complex and demonstrated the crucial role of $\mathrm{HCo}(\mathrm{CO})_{4}$ in the catalytic cycle.

\section{ASSOCIATED CONTENT}

The Supporting Information is available free of charge http://pubs.acs.org.

Experimental details, additional experimental results, characterization data and NMR spectra (PDF).

\section{AUTHOR INFORMATION}

\section{Corresponding Author}

Neal P. Mankad - Department of Chemistry, University of Illinois at Chicago 845 W. Taylor St., Chicago, IL 60607, USA; orcid.org/0000-0001-6923-5164, email: npm@uic.edu

\section{Author}

Maxim R. Radzhabov - Department of Chemistry, University of Illinois at Chicago 845 W. Taylor St., Chicago, IL 60607, USA; orcid.org/0000-0002-6970-9953 email: mradzh2@uic.edu

\section{Funding Sources}

This material is based upon work supported by the U.S. Department of Energy, Office of Science, Office of Basic Energy Sciences, under Award Number DE-SC0021055.

\section{Notes}

The authors declare no competing financial interest.

\section{ACKNOWLEDGMENT}

We thank Dr. Li-Jie Cheng for providing some starting alkylacetylenes for the reaction scope, and Pinku Tung for thoughtful discussions.

\section{REFERENCES}

(1) Spivey, A.; Gripton, C.; Hannah, J. Recent Advances in Group 14 Cross-Coupling: $\mathrm{Si}$ and Ge-Based Alternatives to the Stille Reaction. Curr. Org. Synth. 2004, 1, 211-226.

(2) Song, H. J.; Jiang, W. T.; Zhou, Q. L.; Xu, M. Y.; Xiao, B. Structure-Modified Germatranes for Pd-Catalyzed Biaryl Synthesis. ACS Catal. 2018, 8, 9287-9291.

(3) Fricke, C.; Sherborne, G. J.; Funes-Ardoiz, I.; Senol, E.; Guven, S.; Schoenebeck, F. Orthogonal Nanoparticle Catalysis with Organogermanes. Angew. Chemie Int. Ed. 2019, 58, 1778817795.

(4) Fricke, C.; Dahiya, A.; Reid, W. B.; Schoenebeck, F. GoldCatalyzed C-H Functionalization with Aryl Germanes. ACS Catal. 2019, 9, 9231-9236.

(5) Fricke, C.; Schoenebeck, F. Organogermanes as Orthogonal Coupling Partners in Synthesis and Catalysis. Acc. Chem. Res. 2020, 58, 13.

(6) Tamao, K.; Kiso, Y.; Sumitani, K.; Kumada, M. Alkyl Group Isomerization in the Cross-Coupling Reaction of Secondary Alkyl Grignard Reagents with Organic Halides in the Presence of Nickel-Phosphine Complexes as Catalysts. J. Am. Chem. Soc. 1972, 94, 9268-9269.

(7) Baba, S.; Negishi, E. ichi. A Novel Stereospecific AlkenylAlkenyl Cross-Coupling by a Palladium- or Nickel-Catalyzed Reaction of Alkenylalanes with Alkenyl Halides. Journal of the American Chemical Society. American Chemical Society October 1976, pp 6729-6731.

(8) Denmark, S. E.; Sweis, R. F.; Wehrli, D. Fluoride-Promoted Cross-Coupling Reactions of Alkenylsilanols. Elucidation of the Mechanism through Spectroscopic and Kinetic Analysis. J. Am. Chem. Soc. 2004, 126, 4865-4875.

(9) Sousa, A. C. A.; Pastorinho, M. R.; Takahashi, S.; Tanabe, S. History on Organotin Compounds, from Snails to Humans. Environmental Chemistry Letters. Springer March 2014, pp 117-137.

(10) Grün, F. Obesogens. Curr. Opin. Endocrinol. Diabetes Obes. 2010, 17, 453-459.

(11) Pagliarani, A.; Nesci, S.; Ventrella, V. Toxicity of Organotin Compounds: Shared and Unshared Biochemical Targets and Mechanisms in Animal Cells. Toxicology in Vitro. Pergamon March 2013, pp 978-990.

(12) Kinzel, T.; Zhang, Y.; Buchwald, S. L. A New Palladium Precatalyst Allows for the Fast Suzuki-Miyaura Coupling Reactions of Unstable Polyfluorophenyl and 2-Heteroaryl Boronic Acids. J. Am. Chem. Soc. 2010, 132, 14073-14075.

Cox, P. A.; Reid, M.; Leach, A. G.; Campbell, A. D.; King, E. J.; Lloyd-Jones, G. C. Base-Catalyzed Aryl-B(OH)2 Protodeboronation Revisited: From Concerted Proton Transfer to Liberation of a Transient Aryl Anion. J. Am. Chem. Soc. 2017, 139, 13156-13165.

(14) Dobrzyński, D.; Boguszewska-Czubara, A.; Sugimori, K Hydrogeochemical and Biomedical Insights into Germanium Potential of Curative Waters: A Case Study of Health Resorts in the Sudetes Mountains (Poland). Environ. Geochem. Health 2017, 40, 1335-1375.

(15) Piers, E.; Lemieux, R. Platinum-Catalysed Addition of Trimethylgermane to 1-Trimethylsilylalk-1- Ynes: A Convenient Synthesis of Functionalised 2Trimethylgermylalk-1-Enes. J. Chem. Soc. Perkin Trans. 1 1995, No. 1, 3-5.

(16) Bowman, W. R.; Krintel, S. L.; Schilling, M. B. Tributylgermanium Hydride as a Replacement for Tributyltin Hydride in Radical Reactions. Org. Biomol. Chem. 2004, 2, 585-592.

Schwier, T.; Gevorgyan, V. Trans- and Cis-Selective Lewis Acid Catalyzed Hydrogermylation of Alkynes. Org. Lett. 2005, 7, 5191-5194

Torres, N. M.; Lavis, J. M.; Maleczka, R. E. Reactions of Vinyltributylgermanes and Aryl Halides under Heck 
Wnuk, S. F.; Garcia, P. I.; Wang, Z. Radical-Mediated Silyl- and Germyldesulfonylation of Vinyl and ( $\alpha$-Fluoro)Vinyl Sulfones: Application of Tris(Trimethylsilyl)Silanes and Tris(Trimethylsilyl)Germanes in Pd-Catalyzed Couplings. Org. Lett. 2004, 6, 2047-2049.

(20) Henry, M. C.; Downey, M. F. Triphenylgermane Addition Reactions. J. Org. Chem. 1961, 26, 2299-2300.

(21) Debrauwer, V.; Turlik, A.; Rummler, L.; Prescimone, A.; Blanchard, N.; Houk, K. N.; Bizet, V. Ligand-Controlled Regiodivergent Palladium-Catalyzed Hydrogermylation of Ynamides. J. Am. Chem. Soc. 2020, 142, 11153-11164.

(22) Roşca, D. A.; Radkowski, K.; Wolf, L. M.; Wagh, M.; Goddard, R.; Thiel, W.; Fürstner, A. Ruthenium-Catalyzed Alkyne Trans-Hydrometalation: Mechanistic Insights and Preparative Implications. J. Am. Chem. Soc. 2017, 139, 24432455.

(23) Schweizer, S.; Tresse, C.; Bisseret, P.; Lalevée, J.; Evano, G.; Blanchard, N. Stereodivergent Hydrogermylations of Trifluoromethylated Alkynes and Their Applications in Cross-Coupling Reactions. Org. Lett. 2015, 17, 1794-1797.

(24) De La Vega-Hernández, K.; Romain, E.; Coffinet, A.; Bijouard, K.; Gontard, G.; Chemla, F.; Ferreira, F.; Jackowski, O.; PerezLuna, A. Radical Germylzincation of $\alpha$-HeteroatomSubstituted Alkynes. J. Am. Chem. Soc. 2018, 140, 1763217642.

(25) Nozaki, K.; Ichinose, Y.; Wakamatsu, K.; Oshima, K.; Utimoto, K. Et3B Induced Stereoselectivity Radical Addition of $\mathrm{Ph} 3 \mathrm{GeH}$ to Carbon-Carbon Multiple Bonds and Its Application to Isomerization of Olefins. Bull. Chem. Soc. Jpn. 1990, 63, 2268-2272.

(26) Ichinose, Y.; Oda, H.; Oshima, K.; Utimoto, K. Palladium Catalyzed Hydrostannylation and Hydrogermylation of Acetylenes. Bulletin of the Chemical Society of Japan. 1987, pp 3468-3470.

(27) Wada, F.; Abe, S.; Yonemaru, N.; Kikukawa, K.; Matsuda, T. Catalytic Behavior of Rhodium(I) Complexes in Hydrogermylation and Hydrosilylation of Phenylacetylene. Bull. Chem. Soc. Jpn. 1991, 64, 1701-1703.

(28) Furukawa, N.; Kourogi, N.; Seki, Y.; Kakiuchi, F.; Murai, S. Transition Metal-Catalyzed Dehydrogenative Germylation of Olefins with Tri-n-Butylgermane. Organometallics 1999, 18, 3764-3767.

(29) Itazaki, M.; Kamitani, M.; Nakazawa, H. Trans-Selective Hydrogermylation of Alkynes Promoted by Methyliron and Bis(Germyl)Hydridoiron Complexes as a Catalyst Precursor. Chem Commun 2011, 47, 7854.

(30) Liang, H.; Ji, Y. X.; Wang, R. H.; Zhang, Z. H.; Zhang, B. VisibleLight-Initiated Manganese-Catalyzed E-Selective Hydrosilylation and Hydrogermylation of Alkynes. Org. Lett. 2019, 21, 2750-2754.

(31) Cheng, L. J.; Mankad, N. P. Heterobimetallic Control of Regioselectivity in Alkyne Hydrostannylation: Divergent Syntheses of $\alpha$-A Nd (E)- $\beta$-Vinylstannanes via Cooperative Sn-H Bond Activation. J. Am. Chem. Soc. 2019, 141, 37103716.

(32) Sexual Chemistry von Lara V. Marks | ISBN 978-0-30016791-7 | Fachbuch online kaufen - Lehmanns.de.

(33) eBook: Adolescent Health Care von Robert W. Blum | ISBN 978-1-4832-7738-7 | Sofort-Download kaufen Lehmanns.de.

(34) Brennessel, W. W.; Ellis, J. E. Naphthalene and Anthracene Cobaltates(1-): Useful Storable Sources of an Atomic Cobalt Anion. Inorg. Chem. 2012, 51, 9076-9094.

(35) Konno, T.; Taku, K. I.; Yamada, S.; Moriyasu, K.; Ishihara, T. Remarkable Access to Fluoroalkylated Trisubstituted Alkenes via Highly Stereoselective Cobalt-Catalyzed Hydrosilylation Reaction of Fluoroalkylated Alkynes. Org. Biomol. Chem. 2009, 7, 1167-1170.

(36) Heck, R. F.; Breslow, D. S. The Reaction of Cobalt Hydrotetracarbonyl with Olefins. J. Am. Chem. Soc. 1961, 83, 4023-4027.

(37) Halpern, J. Organometallic Chemistry at the Threshold of a New Millennium. Retrospect and Prospect. In Pure and
Applied Chemistry; Walter de Gruyter GmbH, 2001; Vol. 73, pp 209-220.

(38) Dahan, F.; Jeannin, Y. Molecular and Crystal Structure of (+)Tetracarbonyl(Methyl-1-Naphthylphenylgermyl)-Cobalt. J. Organomet. Chem. 1977, 136, 251-258.

(39) Moore, E. J.; Sullivan, J. M.; Norton, J. R. Kinetic and Thermodynamic Acidity of Hydrido Transition-Metal Complexes. 3. Thermodynamic Acidity of Common Mononuclear Carbonyl Hydrides. J. Am. Chem. Soc. 1986, 108, 2257-2263.

(40) Chatani, N.; Fujii, S.; Yamasaki, Y.; Murai, S.; Sonoda, N. Cobalt Carbonyl Catalyzed Reactions of Esters and Lactones with Hydrosilane and Carbon Monoxide. A Novel Synthetic Method for the Introduction of the Siloxymethylidene Group. J. Am. Chem. Soc. 1986, 108, 7361-7373.

(41) Chatani, N.; Murai, S. HSiR3/CO as the Potent Reactant Combination in Developing New Transition-Metal-Catalyzed Reactions. Synlett 1996, 1996, 414-424.

(42) Kramer, J. W.; Joh, D. Y.; Coates, G. W. Carbonylation of Epoxides to Substituted 3-Hydroxy- $\alpha$-Lactones. Org. Lett. 2007, 9, 5581-5583.

(43) Studer, A.; Curran, D. P. Catalysis of Radical Reactions: A Radical Chemistry Perspective. Angew. Chemie - Int. Ed. 2016, 55, 58-102.

(44) Roh, S. W.; Choi, K.; Lee, C. Transition Metal Vinylidene- and Allenylidene-Mediated Catalysis in Organic Synthesis. Chem. Rev. 2019, 119, 4293-4356. 


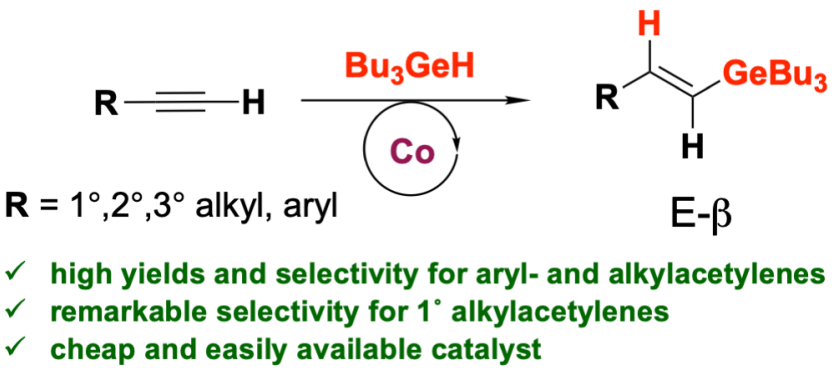

